\title{
A Case of Horizontal Partial Laryngectomy for Laryngeal Trauma
}

\author{
Jong Gyun $\mathrm{Ha}^{1}$, Ah Young Park ${ }^{2}$, Byeong Il Choi ${ }^{2}$, and Hyun Jun Hong ${ }^{2 *}$ \\ ${ }^{1}$ Department of Otorhinolaryngology, Yonsei University College of Medicine, Seoul; and \\ ${ }^{2}$ Department of Otorhinolaryngology, Yonsei University College of Medicine, Gangnam Severance Hospital, Seoul, Korea
}

\section{후두 외상 환자에서 수평적 후두 부분절제술의 유용성 1예}

하종균 ${ }^{1} \cdot$ 박아영 $^{2} \cdot$ 최병일 ${ }^{2} \cdot$ 홍현준 $^{2 *}$

연세대학교 의과대학 이비인후과학교실, ${ }^{1}$ 연세대학교 의과대학 강남세브란스병원 이비인후과학교실 ${ }^{2}$

\author{
Received August 11, 2013 \\ Revised October 31, 2013 \\ Accepted October 31, 2013 \\ Address for correspondence \\ Hyun Jun Hong, MD, PhD \\ Department of Otorhinolaryngology- \\ Head and Neck Surgery, \\ Catholic Kwandong University \\ College of Medicine, \\ International St. Mary's Hospital, \\ 25 Simgok-ro 100beon-gil, Seo-gu, \\ Incheon 404-834, Korea \\ Tel +82-32-290-3051 \\ Fax +82-32-290-3050 \\ E-mail hyunjun.hong@gmail.com \\ *Current affiliation: Department of \\ Otorhinolaryngology-Head and \\ Neck Surgery, Catholic Kwandong \\ University College of Medicine, \\ International St. Mary's Hospital, \\ Incheon, Korea
}

Laryngeal trauma is rare compared to other head and neck traumas, but it occurs, it can be life threatening. As for treatment, a laryngeal fracture that involves displacement of cartilage or extensive injury requires appropriate surgical treatments. For severe laryngeal fractures, conservative management is usually preferred with placing a stent to prevent laryngeal stenosis. But the downside of placing stents in the larynx includes the risk of granulation and infection. In this report, the authors describe a 35-year-old patient, who was diagnosed with blunt laryngeal trauma and treated by Horizontal partial laryngectomy. The patient's post-operative breathing and voice were fair, and airway stenosis did not occur afterwards.

Korean J Otorhinolaryngol-Head Neck Surg 2015;58(2):120-3

Key Words Cartilage fracture $\cdot$ Laryngeal cartilages $\cdot$ Laryngectomy $\cdot$ Larynx $\cdot$ Trauma.
서 론

후두 외상은 다른 두경부 외상에 비하면 흔하지 않으나 적 절한 진단 및 치료가 이루어지지 않을 경우 치명적인 손상으 로 심각한 증상이 초래될 수 있다. 후두 외상 치료는 보존적 치료와 수술적 치료로 나눌 수 있으며, 치료 후 기도 협착의 방지와 발성기능의 유지가 중요한 치료 목적이다. 심한 후두 외상의 치료는 일반적으로 손상 입은 후두를 정복하고 후두 내 스텐트를 거치하여 기도를 유지하는 것이 우선적으로 고려 되지만, 기도 협착과 감염, 발성기능 저하의 가능성이 있다. 저
자들은 외상으로 인한 심한 후두 골절 환자에서 수평적 부분 후두절제술을 시행하여 기도를 보존한 1 예에 대하여 문헌 고 찰과 함께 보고한다.

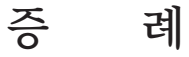

35세 남자 환자는 내원 3일 전 공장에서 프레스 칸막이에 눌려 경부 수상 후 타 병원에서 입원 치료 중 발생한 호흡곤 란을 주소로 본원 전원되었다. 환자의 활력징후는 안정적이 었고 목소리는 정상이었으나 누운 자세에서 호흡곤란을 호소 
하였다. 경부의 개방 손상은 없었고 후두내시경 검사상 양측 성대의 움직임은 정상이었으나 양측 가성대의 점막 손상과 함 께 후두 전벽이 내측으로 전위되어 있었다. X-ray와 전산화 단층촬영에서는 경부 피하 기종 및 종격 기종이 있었고, 갑상 연골 정중선의 골절과 함께 중간 높이에서의 횡행 골절로 골 편이 내측 전위되어 있었다(Fig. 1).

기관 삽관 후 기관절개술 시행하여 기도를 확보하고 갑상 절 흔의 $1 \mathrm{~cm}$ 하방에 수평으로 피부 절개하였다. 윤상연골과 설골 의 손상은 없었으나 갑상연골은 정중선의 골절과 함께 성문상 부 위치에서 수평으로 골절되어 있었다(Fig. 2A and B). 양측 성대는 손상이 없었고 양측 가성대 및 피열연골 근육돌기 위쪽 으로 내측 연골막을 따라서 점막 열상이 관찰되었다(Fig. 2C). 후두 손상에 대한 Cherian 분류로는 중증(major)에 해당하며
Schaefer의 분류로는 group IV 후두 손상에 해당하였다.,2)

후두골절의 상태가 다발적이고 성문 상부의 점막 손상이 심하며, 수상 후 3일이 지나 염증으로 인한 부종이 동반되어 보 존적인 수술 시 육아종 형성 등의 합병증 발생 위험이 높다고 판단되었다. 다행히 성문부가 온전하였고, 갑상연골의 골절선 이 수평적 부분 후두절제술의 절개선과 위치가 유사하여 골 절로 유리된 골절편과 연조직을 제거하고 수평 골절선을 이용 한 수평적 부분 후두절제술을 시행하였다. 양측 갑상연골의 온전한 내측 연골막을 박리하여 가성대, 피열 연골 점막과 봉 합하였고 cross \& tie technique으로 thyro-hyoido-pexy를 시행하였다(Fig. 2D). 후두 내 스텐트는 거치하지 않았다.

술 후 14 일 시행한 후두내시경 소견상 갑상연골의 전위와 후두 부종으로 인한 후두 폐쇄는 완전히 회복되었고 양측 성
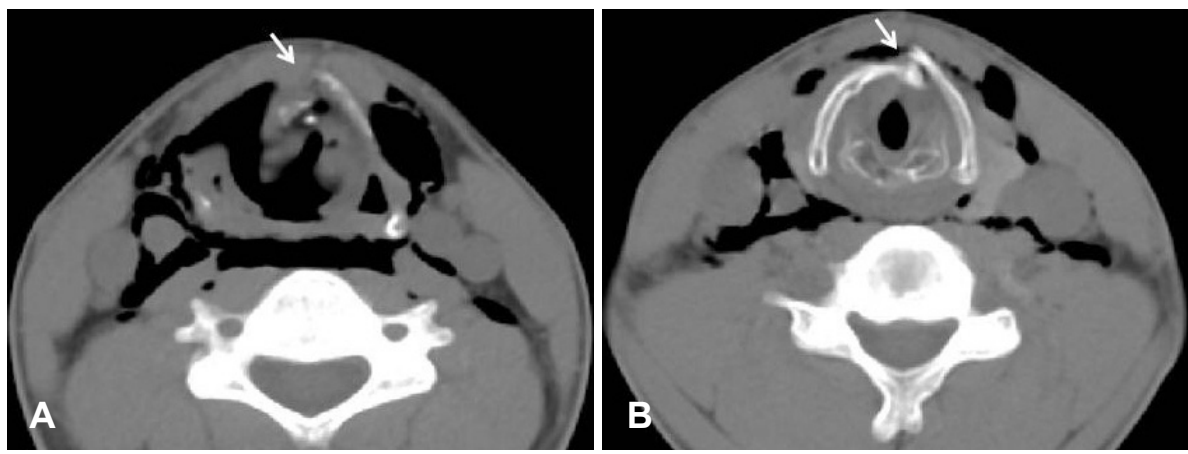

Fig. 1. Preoperative neck CT shows subcutaneous emphysema and swelling on axial scan. The white arrow shows fracture line of thyroid cartilage at the level of thyroid notch (A). The white arrow shows dislocated thyroid cartilage (B).
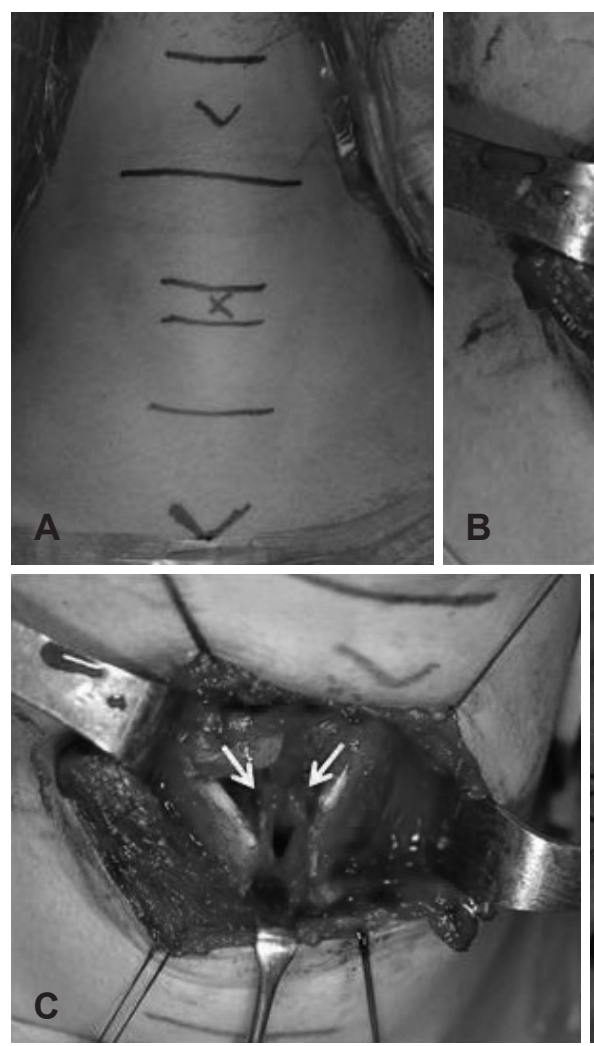
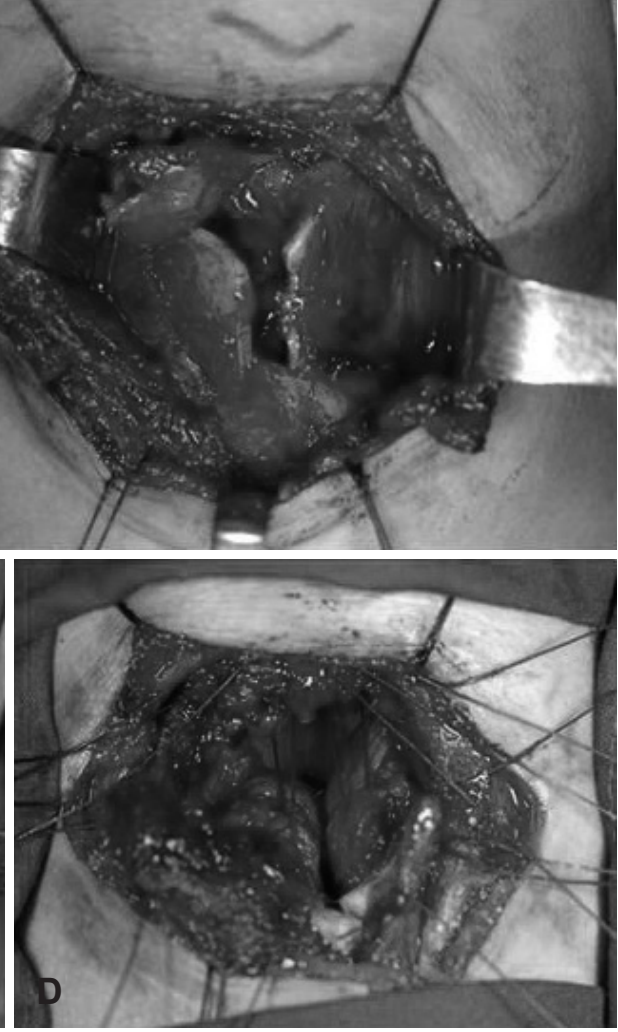

Fig. 2. External blunt laryngeal injury (A). Fracture divides the thyroid cartilage along the midline. Left side of thyroid cartilage has transverse fracture line at the level of supraglottis (B). Laceration of laryngeal mucosa at the supraglottic level. The white arrows show that both true vocal cords were intact $(\mathrm{C})$. Hyoid bone and remained thyroid cartilage were closed with sutures (D). 
대 움직임은 정상이었으며 X-ray 소견상 기도 협착은 관찰되 지 않았다(Fig. 3). 환자는 술 후 21일에 퇴원하였고 술 후 3개 월째 기관절개 부위를 봉합 폐쇄하였다. 수술 후 3 년 동안의
추적관찰 중 환자는 호흡곤란을 호소하지 않았고 CT 및 후두 내시경 검사상 기관 내 육아조직이나 기관 폐쇄 등의 합병증은 관찰되지 않았다(Fig. 4).
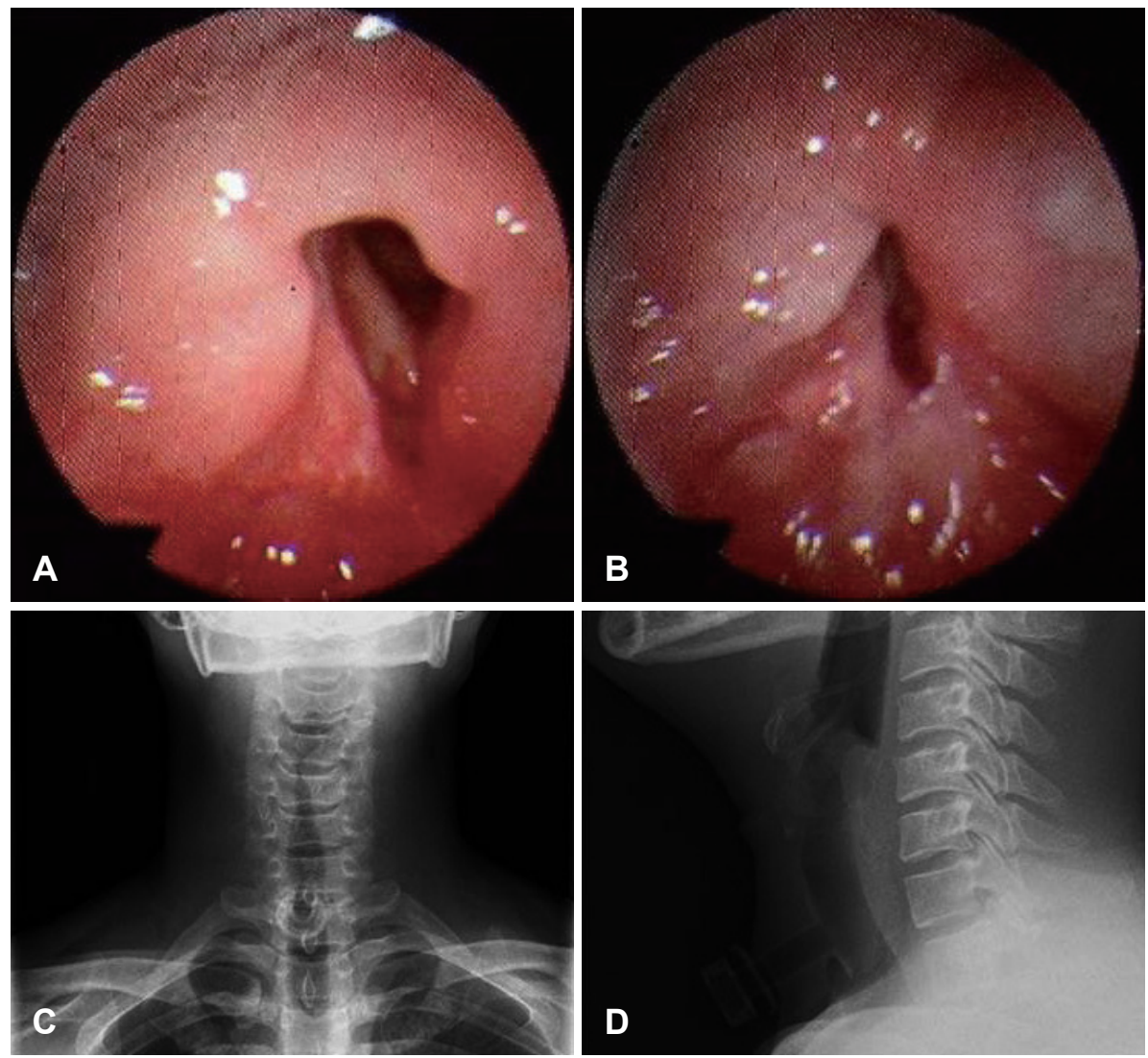

Fig. 3. Laryngoscopic images at postoperation 14 days. There was no vocal cord paralysis ( $A$ and $B$ ). There was no laryngeal stenosis or granulated tissue on simple X-ray images of neck ( $C$ and $D)$.
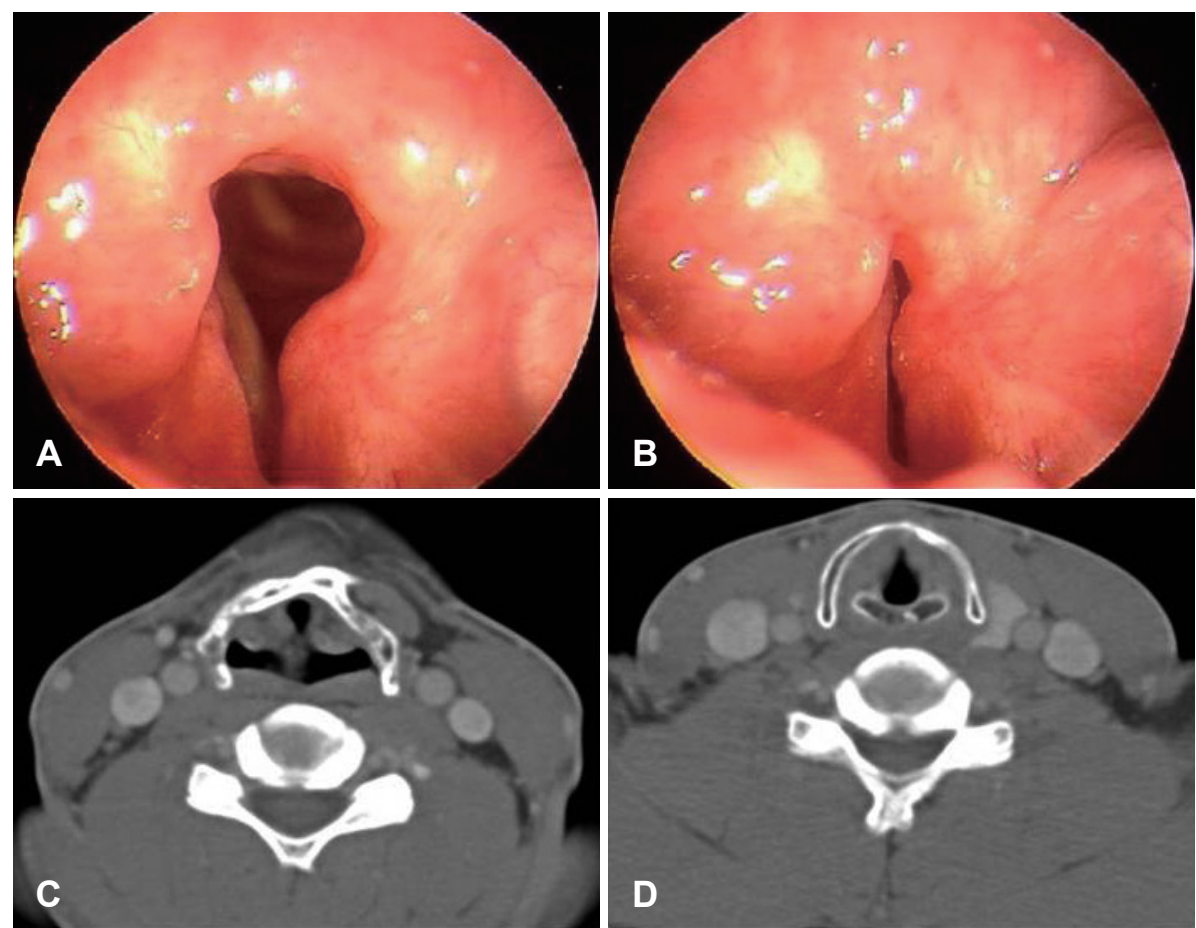

Fig. 4. Laryngoscopic and CT images at post-operation 3 years. There was no subglottic stenosis or granulation ( $A$ and $B$ ). Neck CT shows well recovering of thyroidal cartilage fracture without severe complications (C and D). 


\section{고 찰}

후두기관 손상의 비율은 주요 외상 환자의 $1 \%$ 미만이며, ${ }^{3,4}$ 후두 골절의 빈도는 응급실을 내원하는 14000 42000명 중 1 명으로 보고된다. ${ }^{5)}$ 후두 골절 시 갑상연골의 골절이 가장 흔 하다고 알려져 있으며, 국내에서 후두 외상 환자에서의 갑상 연골 골절의 비율은 $50 \%$ 에서 $73.3 \%$ 로 보고되었다. ${ }^{67)}$

후두 외상의 치료는 보존적 치료와 수술적 치료로 나눌 수 있다. Nahum ${ }^{8}$ 은 후두 내 부종, 혈종, 타박상, 비전위 골절, 전연합부나 자유연 부위를 제외한 곳의 작은 열상 등 가역적 손상에 한해서 보존적 치료를 권유하였다. 보존적 치료를 할 경우 최소 24시간 이상의 관찰이 필요하며 두위 거상, 가습 등 을 하고 급성기의 스테로이드 사용도 가능하다. ${ }^{4}$

후두 외상 시 수술적 치료의 적응증은 점막의 큰 열상과 연 골 노출, 전위연골 골절, 다중 골절, 성대마비, 윤상연골 골절, 성대 전연합의 열상, 윤상 피열 관절 파열 등이다.") 그 시기는 논의의 여지가 있으나 일반적으로 수상 24시간 이내에 조기 수술을 할 것을 권유하고 있다. ${ }^{10,11)}$

후두 골절의 수술적 치료는 고정판이나 봉합 등의 방법으로 정복 고정 후 스텐트를 사용하여 기도 협착을 예방하는 것이 일반적이다. 하지만 스텐트는 육아 조직 형성, 궤양 및 감염의 위험도가 증가할 수 있는 등의 단점이 있으며, 많은 저자들이 중상 환자에서 스텐트 사용 유무에 따른 예후의 차이가 없거 나 스텐트를 쓰지 않은 경우에서 음성이나 기도유지 등의 결과 가 더 좋았다는 보고를 하였다. Leopold ${ }^{12)}$ 는 이는 삽입한 스 텐트 주위의 염증반응에 의한 결과라고 생각하였고, Thompson 등, ${ }^{13)}$ Bong 등 ${ }^{14)}$ 은 대개 후두 손상이 심할 때 스텐트 삽입 이 시행되는 것과도 연관 있을 것으로 추측하였다.

본 증례에서는 갑상연골의 다발성 골절로 인해 골절편과 유리된 연조직, 후두 점막의 괴사 가능성과, 스텐트 삽입 시 육 아조직 형성 가능성이 높다고 판단되었다. 다행히 심한 후두 골절에도 불구하고 성문부의 직접적인 손상이 없었고 골절 선이 후두실 상부에 수평하게 있으면서 그 위치가 마침 수평 적 부분 후두절제술의 절개선과 비슷하여 수평적 부분 후두 절제술을 시행하였다. 수평적 부분 후두절제술은 $\mathrm{T} 1$ 과 $\mathrm{T} 2$ 성문 상부암에서 시행하는 술식의 하나로, 성대를 보존하면서 성문상부의 구조물들을 제거하여 호흡, 발성, 연하 기능을 유 지할 수 있다. 수술 후 3 년 동안의 후두내시경 검사 및 경부 CT 검사에 따르면 육아 조직의 형성 없이 기도가 잘 유지되었다.

기존의 문헌을 조사하였을 때, 후두 외상 또는 후두 외상 후 후유증의 치료를 위해 부분 후두절제술을 시행한 사례들이
보고된 바 있었다. 이 중 몇몇의 사례에서는 후두 외상 후 지 연된 처치로 보존적 수술의 성공률이 낮다고 판단되어 시행 되었으며, 일부 사례에서는 선택적으로 부분 후두절제술을 시 행하였다. ${ }^{1)}$ Consalici와 Dall'Olio ${ }^{15}$ 는 교통사고로 다발성 후 두 골절을 입은 33세 여자 환자에서 supracricoid laryngectomy with crico-hyoido-epiglottopexy를 선택적으로 시행 하여 기도협착 및 연하곤란 등의 후유증 없이 회복한 사례를 보고하였다. 동일 증례의 논의에서 심한 후두 골절 환자에서 부분 후두절제술이 특수한 경우에 있어서 유용한 선택이 될 수 있으며 보존적인 수술과 비교하였을 때 안정적인 예후와 음성 회복을 기대할 수 있다고 주장하였다.

후두 외상에서 수평적 후두 부분절제술은 일반적인 치료법 은 아니지만, 심한 다발성의 골절이 동반되어 있어 보존적인 수술을 시행할 경우 예후가 나쁠 것으로 기대되거나 수상 후 빠른 처치가 이루어지지 못해 지연된 처치가 적극적으로 이 루어져야 할 때 고려할 만한 대안이 될 수 있다.

\section{REFERENCES}

1) Cherian TA, Rupa V, Raman R. External laryngeal trauma: analysis of thirty cases. J Laryngol Otol 1993;107(10):920-3.

2) Schaefer SD, Close LG. Acute management of laryngeal trauma. Update. Ann Otol Rhinol Laryngol 1989;98(2):98-104.

3) Gussack GS, Jurkovich GJ, Luterman A. Laryngotracheal trauma: a protocol approach to a rare injury. Laryngoscope 1986;96(6):660-5.

4) Schaefer SD. The treatment of acute external laryngeal injuries. 'State of the art'. Arch Otolaryngol Head Neck Surg 1991;117(1):35-9.

5) Fuhrman GM, Stieg FH 3rd, Buerk CA. Blunt laryngeal trauma: classification and management protocol. J Trauma 1990;30(1):87-92.

6) Hwang EG, Park JJ, Jeon SY, Jung TG, Kang JY, Sung JH. Retrospective analysis of acute laryngeal trauma. Korean J Otolaryngol-Head Neck Surg 1999;42(1):97-101.

7) Tae K, Jeong JS, Park IB, Cho SH, Lee SH, Lee HS. The treatment of acute external laryngotracheal injuries. Korean J Otolaryngol-Head Neck Surg 2005;48(1):84-8.

8) Nahum AM. Immediate care of acute blunt laryngeal trauma. J Trauma 1969;9(2):112-25.

9) Bent JP 3rd, Silver JR, Porubsky ES. Acute laryngeal trauma: a review of 77 patients. Otolaryngol Head Neck Surg 1993;109(3 Pt 1): 441-9.

10) Schaefer SD. Management of acute blunt and penetrating external laryngeal trauma. Laryngoscope 2014;124(1):233-44.

11) Kuttenberger JJ, Hardt N, Schlegel C. Diagnosis and initial management of laryngotracheal injuries associated with facial fractures. J Craniomaxillofac Surg 2004;32(2):80-4.

12) Leopold DA. Laryngeal trauma. A historical comparison of treatment methods. Arch Otolaryngol 1983;109(2):106-12.

13) Thompson JN, Strausbaugh PL, Koufman JA, Kohut RI. Penetrating injuries of the larynx. South Med J 1984;77(1):41-5.

14) Bong JP, Yu KW, Hong KS, Rhim GI, Lee JK, Heo W. Management of Acute Laryngeal Trauma Patients. Korean J Otolaryngol-Head Neck Surg 1998;41(11):1459-63.

15) Consalici R, Dall'Olio D. Severe laryngeal fracture treated by supracricoid laryngectomy. J Laryngol Otol 2010;124(11):1239-41. 